\title{
SISTEM PENCARIAN LONTAR BERBASIS WEB DENGAN METODE VECTOR SPACE MODEL PADA DINAS KEBUDAYAAN PROVINSI BALI \\ I Kadek Yuda Setiadi ${ }^{1}$, Made Sudarma ${ }^{2}$, Duman Care Khrisne ${ }^{3}$ \\ Program Studi Teknik Elektro Fakultas Teknik Universitas Udayana - Bali Email: yudhasetiadi2012@gmail.com ${ }^{1}$, imasudarma@gmail.com ${ }^{2}$, duman@unud.ac.id ${ }^{3}$
}

\begin{abstract}
Abstrak
Penelitian ini bertujuan untuk membantu dalam pencarian gambar digitalisasi lontar dengan Information Retrieval Sistem yang dibangun menggunakan metode Vector Space Model Pengujian sistem pencarian menghasilkan sistem pencarian lontar yang mendapatkan nilai recall: $75.4 \%$ dan precision: $100 \%$ berdasarkan grafik analisis receiver operating characteristic (ROC). Pengujian dengan System Usability Scale (SUS) yang diuji di Dinas Kebudayaan Provinsi Bali mendapat nilai tertinggi pada pertanyaan poin 1,5 dan 7 yang mencapai 42.
\end{abstract}

Kata kunci: Lontar, ROC, SUS, vector space model

\section{Abstract}

This study aims to assist in the search for lontar images with Information Retrieval System built using the Vector Space Model method. The search system testing resulted in a lontar search system that received recall values: $75.4 \%$ and precision: $100 \%$ based on the graph of the receiver operating characteristic (ROC) analysis. Testing with System Usability Scale (SUS) tested at the Bali Provincial Culture Office got the highest score on statement point 1, 5 and 7 which reached 42.

Key Words: Lontar, ROC, SUS, vector space model

\section{PENDAHULUAN}

Lontar adalah daun dari pohon tal yang dikeringkan, lontar merupakan media untuk menulis karya sastra. Pelestarian budaya Bali berupa lontar saat ini menjadi perhatian banyak kalangan mulai dari pemerintah dan masyarakat Bali khususnya. Pelestarian ini dapat dilakukan dengan digitalisasi lontar [1].

Digitalisasi lontar telah dilakukan oleh Dinas Kebudayaan Pemerintah Provinsi Bali sejak tahun 2010 hingga pertengahan 2012, jumlah lontar yang telah melalui proses digitalisasi sebanyak tujuh persen dari jumlah lontar yang disimpan sekitar 6000 lontar. Banyaknya gambar lontar yang disimpan menimbulkan permasalahan baru dalam pencarian lontar yaitu, menyebabkan proses pencarian gambar lontar semakin lama. Hal ini tidak dapat dihindari, karena di Dinas
Kebudayaan Pemerintah Provinsi Bali belum tersedia sistem pencarian gambar lontar. Tidak tersedianya sistem pencarian gambar lontar menyebabkan pustakawan dan pelajar mengalami kesulitan dalam mencari dan mempelajari lontar [2].

Vector Space Model (VSM) adalah metode yang paling sederhana dalam sistem temu kembali informasi, Vector Space Model merupakan model Iformation Retrieval yang mempresentasikan dokumen dan query dalam vektor dimensional. Konsep dasar dari VSM adalah menghitung jarak antar dokumen kemudian mengurutkan berdasarkan tingkat kedekatannya.

Pada penelitian ini dibangun sebuah Information Retrieval System yang diterapkan dalam sebuah sistem penyimpanan arsip lontar di Dinas Kebudayaan Provinsi Bali. Metode 
VSM digunakan dalam pembobotan pada setiap dokumen alih bahasa lontar yang yang dimasukan ke dalam sistem dan diterapkan dalam proses pencarian, yaitu untuk mengurutkan hasil pencarian berdasarkan tingkat relevansi informasi dengan query. Aplikasi pencarian ini akan menampilkan lontar-lontar yang terdapat di Dinas Kebudayaan Pemerintah Provinsi Bali dalam bentuk citra digital dan menampilkan alih bahasa lontar dalam bentuk text.

\section{KAJIAN PUSTAKA}

\subsection{Lontar}

Kata lontar memiliki kaitan erat terhadap bahan yang menjadi dasar dalam pembuatannya, yaitu daun tal (sejenis daun palma/borassus flabelliformis). Lontar adalah salah satu budaya yang ada di Bali, lontar telah diakui dan menjadi warisan budaya dunia. Goresan artistik yang terdapat di atas daun lontar adalah aksara Bali. Aksara Bali merupakan bahasa yang telah mengambil fungsi dan peran sebagai lambang identitas masyarakat Bali. Aksara Bali adalah sarana atau wahana untuk mengungkapkan mengenai kebudayaan yang ada di Bali [3].

\subsection{Vector Space Model}

Vector Space Model (VSM) adalah metode untuk mengamati tingkat kecocokan atau kesamaan term dengan cara pembobotan term. Pada Vector Space Model, sebuah istilah dipresentasikan kedalam sebuah dimensi ruang vector. Relevansi sebuah dokumen ke sebuah query didasarkan pada similaritas diantara vektor dokumen dan vektor query biasa [4].

\subsection{TF.IDF}

Frekuensi kemunculan term pada suatu dokumen disebut tf.idf. Jenis formula yang digunakan untuk perhitungan term frekuensi (tf) yaitu tf murni (raw tf). Maka rumus umum untuk tf.idf adalah penggabungan dari formula perhitungan raw $\mathrm{tf}$ dengan formula perhitungan idf. tf.idf diperoleh dengan mengalikan term frequency dan inverse document frequency [5].

$$
\begin{aligned}
& w_{i j}=t f_{i j} \times i d f_{j} \\
& w_{i j}=t f_{i j} \times \log \left(D / d f_{j}\right)
\end{aligned}
$$

Keterangan :

$w_{i j}$ : Bobot term $t_{j}$ terhadap dokumen $d_{i}$

$t f_{i j}$ : Jumlah kemunculan $t_{j}$ dalam $d_{i}$

$D$ : Jumlah dokumen di dalam database

$d f_{j}$ : Jumlah dokumen yang mengandung

term $t_{j}$

\subsection{Similarity Measure}

Setelah bobot dokumen diketahui, maka dilakukan proses perangkingan dokumen berdasarkan tingkat relevansi dokumen dengan query. Penentuan relevansi dokumen dengan query dipandang sebagai pengukur kesamaan (similarity measure) antara vektor dokumen dengan vektor query. Semakin mirip suatu vektor dokumen dengan vektor query maka dokumen dapat dipandang semakin relevan dengan query [6].

$\operatorname{sim}\left(Q, D_{i}\right)=\frac{\sum_{j=1}^{t} w_{q j} \cdot w_{i j}}{\sqrt{\sum_{j=1}^{t}\left(w_{i j}\right)^{2} \times \sum_{j=1}^{t}\left(w_{q j}\right)^{2}}}$

\subsection{Recall and Precision}

Evaluasi dalam Information Retrieval System dipengaruhi oleh dua parameter, yaitu recall $(R)$ dan precision $(P)$. Recall adalah rasio antara dokumen relevan yang berhasil ditemukembalikan dari seluruh dokumen relevan yang ada dalam sistem. Precision adalah rasio dokumen relevan yang berhasil ditemukembalikan dari seluruh dokumen yang berhasil ditemukembalikan [7].

$$
\begin{aligned}
& P=\frac{\text { kata yang dipisahkan dengan benar }}{\text { Jumlah yang dipisahkan }} \\
& R=\frac{\text { kata yang dipisahkan dengan benar }}{\text { Jumlah kata sebenarnya }}
\end{aligned}
$$

\subsection{Usability Testing}

Sistem usability scale (SUS) merupakan salah satu standar dalam pengukuran usabilitas suatu aplikasi dengan menggunakan sepuluh pernyataan tentang usability. Sepuluh pernyataan disusun dengan pernyataan ganjil bernilai positif, dan pernyataan genap bernilai negatif. Skala yang digunakan dari 1 sampai 5 untuk mengekspresikan respon penguji terhadap setiap pernyataan [8].

\section{METODE PENELITIAN}

Data yang digunakan dalam penelitian ini adalah lontar dan alih bahasa lontar yang diperoleh dari Dinas Kebudayaan 
Provinsi Bali. Data lontar dan alih bahasa lontar yang digunakan dalam penelitian adalah sebagai berikut.
a. Bhuwana Mahbah
b. Yama Purwana Tatwa
c. Yama Purana Tatwa
d. Yama Purwa Tatwa
e. Sila Kramaning Aguron-guron

\subsection{Gambaran Umum}

Gambar 1 merupakan cara kerja dari aplikasi. User membuka halaman aplikasi dengan komputer yang terhubung ke Internet. Selanjutnya user mengetikkan keyword dari lontar yang ingin dicari pada halaman aplikasi. Keyword dicocokkan dengan data yang ada di dalam database. Data yang cocok dengan keyword, dikirim dari database ke komputer pengguna. Data yang dikirim berupa gambar dan dokumen tentang lontar.

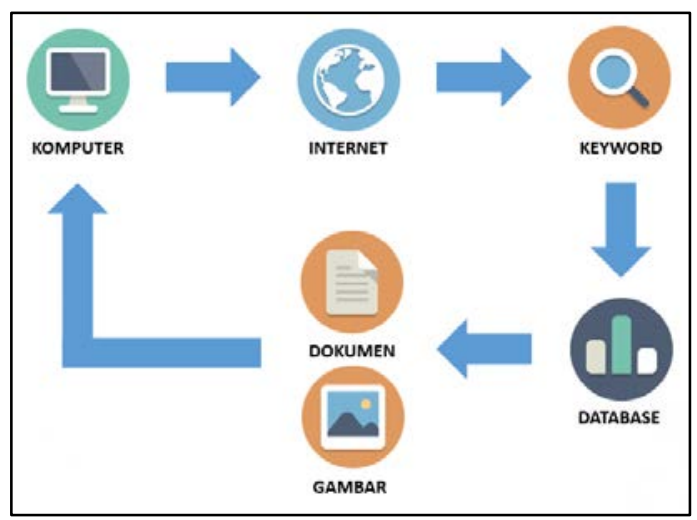

Gambar 1. Gambaran Umum Sistem.

\subsection{Skenario Perhitungan}

Contoh perhitungan bobot dokumen terhadap query yang dimasukan oleh pengguna, dengan menggunakan metode pembobotan tf.idf dengan tiga dokumen yang akan dihitung tingkat kesamaannya dengan query yang dimasukan adalah sebagai berikut

D1: "Yama Purwa Tattwa"

D2: "Yama Purana"

D3: "Tattwa Jnana"

Pengguna memasukan query: "Yama Yama Tattwa"

Total jumlah dokumen dalam koleksi $(D)=3$. Untuk setiap query dan dokumen dalam koleksi, dilakukan pemotongan string berdasarkan tiap kata yang menyusunnya, menghilangkan tanda baca, dan mengubahnya menjadi huruf kecil.

$$
\begin{aligned}
\text { yama } & : \log (3 / 2)=0.176 \\
: \mathrm{df} \quad= & 0.176
\end{aligned}
$$

$$
\begin{aligned}
& : \mathrm{df}+1=1.176 \\
& \text { purwa }: \log (3 / 1)=0.477 \\
& : \mathrm{df} \quad=0.477 \\
& : \mathrm{df}+1=1.477 \\
& \text { tattwa }: \log (3 / 2)=0.176 \\
& : \mathrm{df} \quad=0.176 \\
& : \mathrm{df}+1=1.176 \\
& \text { purana }: \log (3 / 1)=0.477 \\
& : \mathrm{df} \quad=0.477 \\
& : \mathrm{df}+1=1.477 \\
& \text { jnana } \quad: \log (3 / 1)=0.477 \\
& : \mathrm{df} \quad=0.477 \\
& : \mathrm{df}+1=1.477
\end{aligned}
$$

Metode tf.idf digunakan untuk mencari representasi nilai dari tiap dokumen dalam koleksi. Semakin besar nilai perhitungan bobot yang diperoleh maka tingkat relevansi dokumen terhadap query akan semakin tinggi. Berikut adalah contoh perhitungan bobot term query "yama" dalam dokumen 1 (D1). Jumlah kemunculan term "yama" dalam dokumen 1 (D1) adalah sebanyak satu kali (tf = 1), total dokumen dalam koleksi ada sebanyak tiga dokumen ( $D=3)$, dan total dokumen yang mengandung term "yama" adalah dua dokumen $(\mathrm{df}=2)$. Sehingga diperoleh nilai bobot term "yama" pada dokumen 1 (D1):

$$
\begin{aligned}
w_{i j}= & 1 \times(\log (3 / 2)+1) \\
w_{i j}= & 1 \times(0.176+1) \\
& w_{i j}=1.176
\end{aligned}
$$

Nilai term frequency (tf), inverse document frequency (idf), dan idf +1 untuk setiap term dalam masing-masing dokumen, yang dapat di lihat pada Tabel 1.

Tabel 1. Susunan nilai tf dan idf

\begin{tabular}{|c|c|c|c|c|c|}
\hline & Yama & Purwa & Tattwa & Purana & Jnana \\
\hline D1 & 1.176 & 1.477 & 1.176 & 0 & 0 \\
\hline D2 & 1.176 & 0 & 0 & 1.477 & 0 \\
\hline D3 & 0 & 0 & 1.176 & 0 & 1.477 \\
\hline df & 2 & 1 & 2 & 1 & 1 \\
\hline Idf & 0.176 & 0.477 & 0.176 & 0.477 & 0.477 \\
\hline $\begin{array}{r}\text { Idf } \\
+1\end{array}$ & 1.176 & 1.477 & 1.176 & 1.477 & 1.477 \\
\hline
\end{tabular}

Dengan demikian dapat diperoleh nilai bobot (w) untuk setiap term pada query dalam masing-masing dokumen, yang dapat di lihat pada Tabel 2.

\begin{tabular}{|c|c|c|c|c|c|}
\hline & Yama & Purwa & Tattwa & Purana & Jnana \\
\hline D1 & 1.176 & 1.477 & 1.176 & 0 & 0 \\
\hline D2 & 1.176 & 0 & 0 & 1.477 & 0 \\
\hline D3 & 0 & 0 & 1.176 & 0 & 1.477 \\
\hline
\end{tabular}


Tabel 2. Susunan nilai bobot w

Ketika pengguna memasukan query berupa "Yama yama tattwa" dalam sistem pencarian lontar, sistem pencarian lontar akan menghitung vector tf.idf untuk query dan menghitung nilai setiap dokumen yang berhubungan dengan query yang dimasukkan. Nilai bobot query dapat di lihat pada Tabel 3 Ketika menghitung nilai tf.idf untuk query term dibagi frekuensi dengan frekuensi maksimum (2) dan kalikan dengan nilai-nilai idf.

Tabel 3. Nilai bobot query

\begin{tabular}{|l|l|l|l|l|l|}
\hline $\mathrm{q}$ & 1.176 & 0 & 0.588 & 0 & 0 \\
\hline
\end{tabular}

Hitung panjang setiap dokumen dengan query. Menggunakan persamaan 3 fungsi similarity.

$$
\begin{aligned}
& D 1=\sqrt{1.176^{2}+1.477^{2}+1.176^{2}}=2.223 \\
& D 2=\sqrt{1.176^{2}+1.477^{2}}=1.887 \\
& D 3=\sqrt{1.176^{2}+1.477^{2}}=1.887 \\
& q=\sqrt{1.176^{2}+0.588^{2}}=1.314
\end{aligned}
$$

Selanjutnya diitung tingkat kecocokan setiap dokumen dengan query.

$$
\begin{aligned}
& (1.176 * 1.176+1.477 * 0 \\
& \cos \operatorname{Sim}(D 1 . q)=\frac{+1.176 * 1.088+0 * 0+0 * 0)}{(2.223 * 1.314)} \\
& =\frac{2.661}{2.921}=0.91 \\
& (1.176 * 1.176+0 * 0 \\
& \cos \operatorname{Sim}(D 2 . q)=\frac{+0 * 1.008+1.477 * 0+0 * 0)}{(1.887 * 1.314)} \\
& =\frac{1.382}{2.479}=0.557 \\
& (0 * 1.176+0 * 0+1.176 \\
& \operatorname{cosSim}(D 3 . q)=\frac{* 1.088+0 * 0+1.477 * 0)}{(1.887 * 1.314)} \\
& =\frac{1.279}{2.479}=0.515
\end{aligned}
$$

Menurut tingkat kecocokan dokumen dengan query. Urutan dokumen yang ditampilkan menjadi: D1, D2, D3.

\section{HASIL DAN PEMBAHASAN \\ 4.1 Hasil Perancangan}

Hasil perancangan membahas mengenai keluaran atau hasil akhir dari pembangunan sistem pencarian lontar. Gambar 2 merupakan tampilan halaman pencarian lontar, dalam tampilan pencarian lontar terdapat dua menu utama. Pada menu Lontar terdapat hasil pencarian data lontar, sedangkan menu data lontar mengarah ke halaman data lontar yang berfungsi untuk penambahan data lontar, pengubahan data lontar dan penghapusan data lontar. Halaman data lontar bisa dilihat pada gambar 3 .

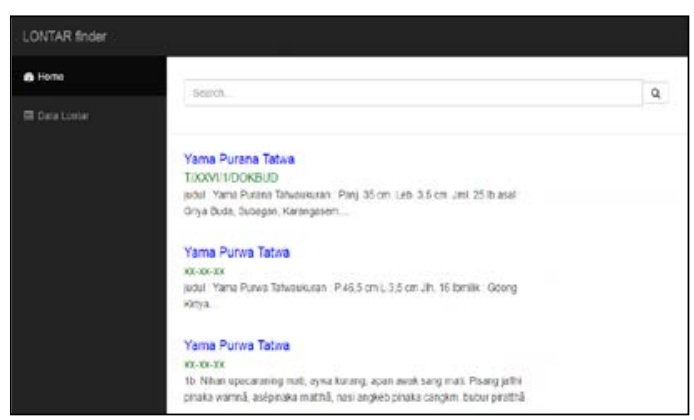

Gambar 2. Halaman pencarian lontar

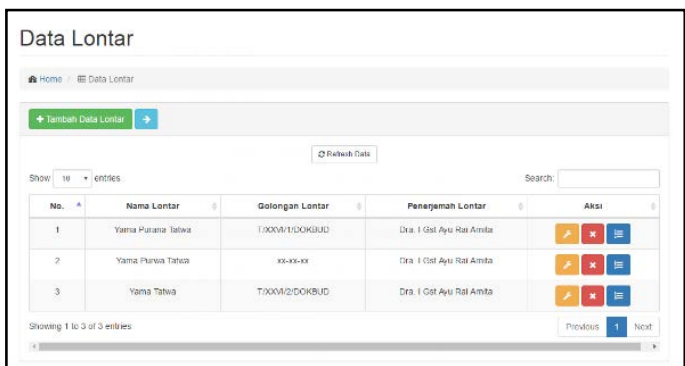

Gambar 3. Tampilan halaman data lontar

\subsection{Pembahasan}

Evaluasi sistem dilakukan dengan metode recall dan precision. Pengujian dilakukan dengan kata yang digunakan sebagai bahan uji seperti yang tertera pada Tabel 4. Pengujian dilakukan dari K1 hingga K15, sesuai dengan kata yang digunakan sebagai bahan uji pada Tabel 4.

Tabel 4. Pengujian Ukuran Marker

\begin{tabular}{|c|l|c|}
\hline $\begin{array}{c}\text { No. } \\
\text { Pengujian }\end{array}$ & Kata Kunci (query) & $\begin{array}{c}\text { Halaman } \\
\text { Relevan }\end{array}$ \\
\hline K1 & Pinak & 6 \\
\hline K2 & Sari & 9 \\
\hline K3 & Maulam & 6 \\
\hline K4 & Krama & 5 \\
\hline K5 & Gading & 1 \\
\hline K6 & Sida Tinambanan & 8 \\
\hline K7 & Nama Swaha & 2 \\
\hline K8 & brata mangan & 2 \\
\hline K9 & Sakeng Sariranta & 1 \\
\hline K10 & Prabhu Pralaya & \\
\hline
\end{tabular}




\begin{tabular}{|c|l|c|}
\hline K11 & Tingkah Nusang Sawa & 3 \\
\hline K12 & Sasab Mararjna Amati & 1 \\
\hline K13 & Reh Suba Kamma & 1 \\
\hline K14 & Nista Duhur Dulange & 1 \\
\hline K15 & Carik Windu Modre & 2 \\
\hline
\end{tabular}

Perhitungan untuk evaluasi sistem dengan metode recall dan precision. Pengujian dilakukan dengan kata yang digunakan sebagai bahan uji seperti yang tertera pada Tabel 4. Pengujian dilakukan sebanyak 5 kali untuk setiap query pengujian. Pengujian dilakukan dengan perhitungan recall dan precision.

Tabel 5 merupakan pengujian recall dan precision satu kata. Berdasarkan pencarian dengan satu kata, tidak terlihat perbedaan antara recall dan precision dalam pengujian K1 hingga K5. Dari pengujian pada Tabel 5 dapat di lihat bahwa nilai rata-rata pencarian satu kata yang didapat adalah sebagai berikut.

Precision : :100\%

Recall : $: 100 \%$

Tabel 5. Pengujian 1 kata

\begin{tabular}{|c|c|c|}
\hline No. Pengujian & Precision (\%) & Recall (\%) \\
\hline K1 & 100 & 100 \\
\hline K2 & 100 & 100 \\
\hline K3 & 100 & 100 \\
\hline K4 & 100 & 100 \\
\hline K5 & 100 & 100 \\
\hline
\end{tabular}

Tabel 6 merupakan pengujian recall dan precision dua kata. Dalam pencarian dengan dua kata, hasil pengujian tabel dua kata terlihat adanya penurunan nilai recall dengan pengujian satu kata. Dari pengujian pada Tabel 6 dapat di lihat bahwa nilai ratarata pencarian dua kata yang didapat adalah sebagai berikut.

$\begin{array}{ll}\text { Precision } & : 100 \% \\ \text { Recall } & : 59.2 \%\end{array}$

Tabel 6. Pengujian 2 kata

\begin{tabular}{|c|c|c|}
\hline No. Pengujian & Precision (\%) & Recall (\%) \\
\hline K6 & 100 & 62.5 \\
\hline K7 & 100 & 59 \\
\hline K8 & 100 & 49.5 \\
\hline
\end{tabular}

\begin{tabular}{|c|c|c|}
\hline K9 & 100 & 50 \\
\hline K10 & 100 & 75 \\
\hline
\end{tabular}

Tabel 7 merupakan pengujian recall dan precision tiga kata. Dalam pencarian dengan tiga kata, hasil pengujian tabel tiga kata terlihat adanya perbedaan dengan pengujian satu kata dan pengujian dua kata tentang nilai recall. Dari pengujian pada Tabel 7 dapat dilihat bahwa nilai rata-rata pencarian tiga kata yang didapat adalah sebagai berikut.

$\begin{array}{ll}\text { Precision } & : 100 \% \\ \text { Recall } & : 67.2 \%\end{array}$

Tabel 7. Pengujian 3 kata

\begin{tabular}{|c|c|c|}
\hline No. Pengujian & Precision (\%) & Recall (\%) \\
\hline K11 & 100 & 33.6 \\
\hline K12 & 100 & 72.2 \\
\hline K13 & 100 & 83.3 \\
\hline K14 & 100 & 71.4 \\
\hline K15 & 100 & 75.5 \\
\hline
\end{tabular}

Dari data pengujian yang didapat pada Tabel 5, 6 dan 7 telah dihasilkan nilai pengujian recall dan precision. Dari pengujian tersebut didapat nilai rata-rata total sebagai berikut.

$\begin{array}{ll}\text { Precision } & : 100 \% \\ \text { Recall } & : 75.4 \%\end{array}$

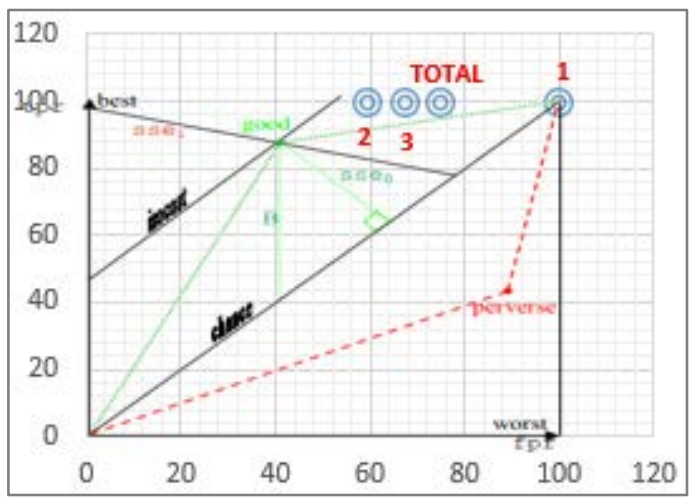

Gambar 4. Grafik analisis ROC perbandingan nilai recall(x) dan precision(y)

Dari Gambar 4 terlihat nilai pengujian recall dan precision dalam grafik analisis ROC, pengujian satu kata mendapat hasil good seperti yang terlihat pada grafik analisis ROC dikarenakan nilai recall dan precision yang mencapai 100\%. Untuk 
pengujian dua dan tiga kata juga mendapat hasil good seperti yang terlihat pada grafik analisis ROC. Dari pengujian tersebut didapat nilai rata-rata total hasil pencarian berdasarkan grafik analisis ROC adalah good.

Pengujian kepada responden dilakukan di Dinas Kebudayaan Provinsi Bali dengan pegawai dan pengunjung sebagai responden untuk dimintai kesediaan menggunakan sistem pencarian lontar. Responden merupakan pegawai dan pengunjung Dinas Kebudayaan Provinsi Bali, masing-masing berjumlah 5 orang. Responden diminta menggunakan Laptop dengan system pencarian lontar yang telah terdapat di dalamnya, lembar skenario, dan lembar angket System Usabilty Scale (SUS).

Gambar 5 merupakan grafik hasil responden Lontar Finder yang diambil. Nilai tertinggi adalah pada responden 2 dan 9 dengan nilai 80 dan nilai terendah mencapai 45 pada responden 10. Rata-rata hasil yang didapat dari semua partisipan adalah 67.5 dengan standar deviasi 10.2 dari hasil rata-rata tersebut dapat diketahui nilai dari aplikasi terdapat pada kualitas bagus lalu dengan standar deviasi 10.2 diketahui rentang jarak rata-rata maksimum dan minimum adalah 10.2 .

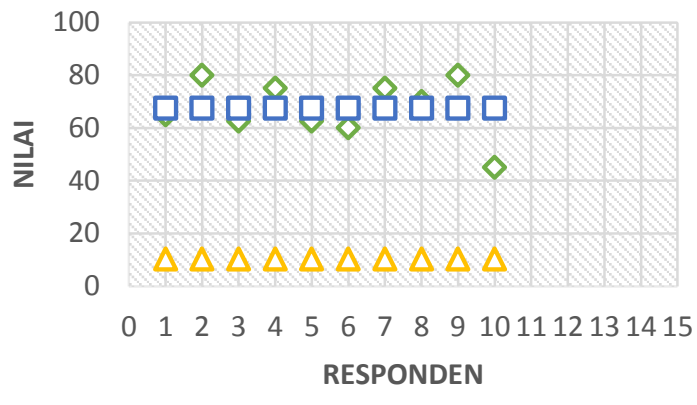

$\checkmark$ Nilai Responden $\quad \square$ Mean $\unlhd$ Standar Deviasi

Gambar 5. Grafik hasil responden

Sistem mendapatkan nilai tertinggi pada pertanyaan poin 1,5 dan 7 yang mencapai 42. Dan nilai terendah pada pertanyaan poin 4 dan 10 yang mencapai 31. Hal ini mengindikasikan bahwa untuk penggunaan aplikasi diperlukan bantuan teknisi yang untuk menjelaskan penggunaan aplikasi.

\section{KESIMPULAN}

Sistem temu kembali informasi yaitu Lontar Finder dapat mencari informasi mengenai judul maupun alih bahasa lontar.

Dalam proses pengindeksan sistem temu kembali informasi yaitu Lontar Finder melalui beberapa tahapan pemrosesan kata, yang diawali dengan parsing, yaitu suatu pemrosesan kata yang di dalamnya terdapat proses untuk mengubah semua huruf dalam dokumen menjadi huruf kecil, selanjutnya dilakukan proses penghilangan tanda baca. Dilanjutkan dengan pemisahan teks menjadi array kata dan diakhiri dengan pemberian bobot ke setiap array kata.

Dalam proses pencarian pada sistem temu kembali informasi yaitu Lontar Finder, proses yang dilalui sama dengan proses pengindeksan akan tetapi dibagian terakhir ditambahkan fungsi similarity yang bertujuan untuk mencocokan query yang dimasukan dengan data yang terdapat dalam database.

Sistem temu kembali informasi Lontar Finder memperoleh hasil yang baik dengan rata-rata recall dan precision mencapai $100 \%$. Sehingga dokumen yang dicari relevan dengan query yang dimasukan.

Pengujian usability system temu kembali informasi Lontar Finder setelah diuji kepada 10 pegawai Dinas Kebudayaan Provinsi Bali mendapatkan nilai rata-rata 67.5, dan mendapat mendapatkan nilai tertinggi pada pertanyaan poin 1, 5 dan 7 yang mencapai 42 .

\section{SARAN}

Algoritma stemming digunakan untuk pengecekan kata dasar, kata berimbuhan, stop word, dan frasa. Frasa adalah gabungan dua kata atau lebih yang besifat non-predikatif (tidak ada yang berkedudukan sebagai predikat). Saat ini algoritma stemming untuk kata-kata dalam Bahasa Bali belum dikembangkan. Untuk membuat aplikasi pencarian lontar menjadi lebih akurat diperlukan adanya algoritma stemming untuk kata-kata dalam Bahasa Bali, sehingga dapat mengurangi ukuran indeks dan menambah akurasi dalam pencarian.

\section{DAFTAR PUSTAKA}

[1] Rai Putra. Lontar Bali Manuskrip Penampang Peradaban Berkarakter. Seminar Nasional Potensi Naskah Lontar Bali yang Bernilai Luhur Dalam Penguatan Jati Diri Bangsa. Bali. 2015. 
[2] Dinas Kebudayaan Provinsi Bali, 2017.

[3] Alit Sancana. Kajian Efektivitas Teknik dan Bahan Konservasi pada Lontar di Bali. Jurnal Konservasi Cagar Budaya Borobudur. 2014.

[4] Aziz, A., Saptono, R. and P.S, K., Implementasi Vector Space Model dalam Pembangkitan Frequently Asked Questions dan Solusi yang Relevan Keluhan Pelanggan. Scientific Journal Informatics, 2(2). 2015.

[5] Basmalah, V., Saptono, R., Widya, S., Analisis Perbandingan Metode Vector Space Model dan Weighted Tree Similarity dengan Cosine Similarity pada kasus Pencarian Informasi Pedoman Pengobatan Dasar di Puskesmas. JURNAL ITSMART ISSN: 2301-7201. 2015.

[6] Kurchaniya, D. and Kumar, P., Analysis of Different Similarity Measures in Image Retrieval Based on Texture and Shape. International Research Journal of Engineering and Technology (IRJET). 2017.

[7] Badrus, Z., Alfian, S., dan Endah, P., Klasifikafi Dokumen Temu Kembali Informasi dengan K-Nearest Neghbour. e-ISSN 2442-5168. 2015.

[8] Ashshidhiqi, G.B.H. Rekomendasi rancangan Information Architecture Website Institusi Pendidikan Tinggi Menggunakan Metode Card Sorting pada Metode Goal-Directed Design. eProceeding of Engineering, Vol 2: 2. 2015. 